\title{
Heart Adaptation Characteristic to Physical Loads in Cyclic Kinds of Sport
}

\author{
Mutaeva I.S. \\ Yelabuga Institute (branch) of Kazan (Privolzhsky) Federal \\ University \\ Yelabuga, Russia \\ mutaeva-i@mail.ru
}

\author{
Petrov R.E. \\ Yelabuga Institute (branch) of Kazan (Privolzhsky) Federal \\ University \\ Yelabuga, Russia \\ romanpetrovrdr@mail.ru
}

\author{
Zhestkova Y.K. \\ Yelabuga Institute (branch) of Kazan (Privolzhsky) \\ Federal University \\ Yelabuga, Russia \\ zhest.13@list.ru
}

\begin{abstract}
Cyclic kinds of sport demand high functional readiness of athletes. A typical feature of competitive activity in cyclic kinds of sport is three regimes of physical load combination. Their ratio at the distance conditions high level of physical working capacity. At the same time, it is very important to provide organism with oxygen, which influences the level of aerobic productivity. In this case the dynamics of heart rate indices during the control distance overcoming can be the source of urgent information about organism adaptation to the loads of different volume and regime.
\end{abstract}

Keywords-athletes; cyclic kinds of sport; heart rate; adaptation; distance.

\section{INTRODUCTION}

A lot of works observed the problem of athletes' organism adaptation in cyclic kinds of sport. The following works should be especially considered: Y.S. Vanyushin (2001), I.K. Vakhitov (2005), M.V. Shaikhislamov (2007), M.Y. Vanyushin (2012) and others. They studied the problem of adaptation during sport, as a necessary part for physiological grounds for physical loads.

There are a lot of research works concerning the questions of heart and respiration role during oxygen provision in terms of physical activity.

\section{LITERATURE REVIEW}

M.Y. Vanyushin, Y.S. Vanyushin (2011), considering the adaptation of cardiorespiratory system of athletes, who go in for different kinds of sport, studied the types cardiorespiratory system reaction to the load of the increasing power. They revealed several types of system reaction: chronotropic, inotropic, respiratory, chronotropic-respiratory and inotropicrespiratory. All these mentioned types show the level of cardiovascular system inclusion into the loads, characterizing different degrees of heart activity tension. The role of heart rate in minute blood volume (MBV) during the loads of different power is mentioned. The authors defined the importance of organism adaptation complex estimation to the loads of different power.

E.A. Zolotova, Y.S. Vanyushin, I.S. Mutaeva (2008), E.A. Zolotova (2010) define the influence of synchronized swimming lessons on children's heart work characterizing the peculiarities of adaptation to the loads of small and big power.

I.S. Mutaeva, A.S. Kuznetsov, I.E. Konovalov, G.Z. Khalikov (2013) analyzing functional readiness of the average distance runners, underlined the necessity of a complex diagnostics for the training loads of different orientation substantiation.

Nurmekivi, 2008; Losnegard, 2015 mention that one of the factors of athletes' high physical working capacity is heart rate activity. Antunes, 2015, underlines that the higher is the volume of blood that heart pushes from the ventricle, the quicker it is delivered to the contracting muscles. Owing to this in cyclic kinds of sport functional heart abilities mainly condition organism endurance (Gasser, 2015; Formenti, 2015; Mendia-Iztueta, 2016).

Petrov R.E., Bekmansurov R.K. (2017), R.E. Petrov, I.S. Mutaeva, A.A. Ionov (2018) considering heart activity during the loads of different power in cyclic kinds of sport for athletes' functional readiness increase, mention that a necessary condition is an effective training means planning.

The aim of this article is the athletes' adaptive abilities analysis according to heart rate indices during control distance overcoming. 


\section{RESEARCH METHODOLOGY}

The authors examined the athletes, who go in for cyclic kinds of sport, such as: cross country skiing, bicycling, track and field athletics (32 people, age range 16-17 years old). Athletes train at sports schools in the groups of sportsmanship improvement. For heart rate registration Polar RC3 GPS (Germany) watch was used.

\section{RESULTS}

Organism adaptive abilities characteristic among athletes, who go in for cyclic kinds of sport through heart rate indices is available, practical and doesn't demand expensive equipment use.

It is a well-known fact that the ability of an athlete to overcome the distance is closely connected with cardiorespiratory system of an organism. In this connection it is convenient to use heart rate indices for the analysis and express-diagnostics, as they characterize physiological state of an organism during different load.

The results of heart rate indices study among athletes, who go in for cyclic kinds of sport, showed that the athletes start with heart rate from 115 till 132 beats per minute. In bicycling heart rate value during the $5^{\text {th }}$ minute achieves 167 beats per minute, in the average distance running heart rate becomes 172-175 beats per minute, in cross country sprint skiing from 175 till 187 beats per minute, showing intensive activity of a heart during the start.

Table I presents heart rate indices during the period of distance overcoming by the athletes depending on a kind of sport.

TABLE I. HEART RATE INDICES AMONG ATHLETES, WHO GO IN FOR CYCLIC KINDS OF SPORT ACCORDING TO THE RESULTS OF THE CONTROL DISTANCE OVERCOMING

\begin{tabular}{|l|c|c|c|}
\hline Heart rate indices, beats/min & $\begin{array}{c}\text { Cross } \\
\text { country } \\
\text { racers }\end{array}$ & $\begin{array}{c}\text { Athletes } \\
\text { average } \\
\text { distance } \\
\text { runner s }\end{array}$ & $\begin{array}{c}\text { Racing } \\
\text { cyclists }\end{array}$ \\
\hline Duration of HR registration & $1: 00: 00$ & $1: 00: 00$ & $1: 00: 00$ \\
\hline HR at rest, beats/min & 62 & 58 & 66 \\
\hline HR min, beats/min & 112 & 115 & 130 \\
\hline HR max, beats/min & 187 & 178 & 189 \\
\hline $\begin{array}{l}\text { Summarized values of HR } \\
\text { during the period of } \\
\text { registration, beats/min }\end{array}$ & 11200 & 12100 & 13200 \\
\hline $\begin{array}{l}\text { HR of recovery at the 3 } \\
\text { minute, beats/min }\end{array}$ & 110 & 108 & 121 \\
\hline
\end{tabular}

The results of HR dynamics analysis helped to mention that $\mathrm{HR}$ at rest in low values is among average distance runners ( 58 beats/min), among cross country racers the dynamics is 62 beats/min and among racing cyclists 66 beats/min.

Summarized HR value during the period of registration $(60$ minutes) was the following: among cross country racers 11200 beats, among the average distance runners 12100 beats and among racing cyclists 13200 beats. Heart rate indices were also analyzed according to the zones of intensity. Among cross country racers distance overcoming in an aerobic zone was $12 \%$ of time. Most part of the distance athletes overcome in a mixed zone $55 \%$ and the rest of the time (33\%) lasts in the anaerobic conditions of distance overcoming. Among the average distance runners distance overcoming in the aerobic zone is $17 \%$ of time, in the mixed zone- $35 \%$ and the rest of the time $48 \%$ lasts in the anaerobic conditions of distance overcoming. Among racing cyclists distance overcoming in the aerobic zone is $9 \%$ of time, in the mixed zone $-38 \%$ and the rest of the time is $56 \%$ lasts in the anaerobic conditions of distance overcoming. Racing cyclists' higher HR indices (189 beats/min) last longer than the indices among cross country racers and the average distance runners.

A long-term analysis of HR indices among the athletes, who go in for cross country skiing, showed that maximum HR values achievement happens during the first part of the distance and their retention depends on athletes' training level. Among racing cyclists maximum HR is achieved quicker, than among the athletes and cross country racers (it is 189-192 beats/min and preserves longer). HR indices variation according to active parts is $\pm 17-23$ beats $/ \mathrm{min}$.

It should be noted that HR indices among the athletes depends on their functional readiness and adaptive reserves of an organism. Nevertheless, we see functional abilities decrease among racing cyclists. It can be explained by the fact that in cyclic kinds of sport there is the number of starts increase, typical for modern sport. In this case the athletes, who have high functional reserve of adaptive capacities, get the advantage.

It is interesting to consider HR indices along the whole distance. Among cross country racers at $10 \mathrm{~km}$ distance HR indices variated from 168 till 178 beats/ min. In $50 \mathrm{~km}$ running cross country racers most of the time had 170 beats/min pulse. Among the average distance runners the range of $\mathrm{HR}$ variations was from 165 till 184 beats/min. Among racing cyclists there were quick HR junctions from the average till maximum values.

\section{CONCLUSION}

The received HR indices prove, that training of athletes in cyclic kinds of sport will be the most effective if during the training lessons not only physical training, but also athletes' individual peculiarities of a functional state at every stage will be taken into consideration. Cyclic kinds of sport are characterized by great volume of aerobic and mixed loads fulfillment, preparing the organism functionally for greater intensity loads.

The dynamics of different intensity running analysis among the athletes, who go in for cyclic kinds of sport, leads to the conclusion about the intensity of running increase among more trained athletes by means of aerobic intensity running decrease. From stage to stage there is specific weight redistribution of the moderate, average and maximum speed of running. Specific weight with maximum speed at the main trainings increases among cross country racers for $8,67 \%$; among athletes for $12,45 \%$ and among racing cyclists for $17,23 \%$. We see specific weight decrease of the aerobic 
[7] Kuznetsova, Z., Kuznetsov, A., Mutaeva, I., Khalikov, G., Zakharova, A. Athletes preparation based on a complex assessment of functional state. In Proceedings of the $3^{\text {rd }}$ International Congress on Sport Sciences Research and Technology support. SCITEPRESS. 2015, pp. 156-160.

[8] Petrov R.E., Bekmansurov R.K. Heart rate dynamics during step-by-step increasing load among cross country racers during the preparatory period. Modern science intensive technologies. 2017, 2, pp. 147-151

[9] Petrov R.E., Mutaeva I.S., Ionov A.A. Aerobic threshold and cardiac system potentialities determination among cross country skiers (male) on the basis of step-by-step increasing ergometric load. The Russian Journal of Physical Education and Sport. 2018; vol. 13(3), pp. 137-146. DOI 10.14526/02_2018_326

[10] Shaikheslamova M.V. Age related gender characteristics and the mechanisms of adaptive reactions among 7-15 year-old children. Doctor's thesis. Kazan. 2008, 37.

[11] Nurmekivi, A., Karu, T., Pihl, E., Jürimäe, T., Teppan, J. Metabolic effect of strength endurance exercise complex in young cross-country skiers. Biology of Sport. 2008, vol. 25(4), pp. 297-306.

[12] Losnegard, T., Andersen, M., Spencer, M., Hallén, J. Effects of active versus passive recovery in sprint cross-country skiing. International Journal of Sports Physiology and Performance. 2015, vol. 10(5), pp. 630635.

[13] Antunes, A.H., Alberton, C.L., Finatto, P., Pinto, Stephanie S.; Cadore, Eduardo L., Zaffari, P., Kruel, L.F.M. Active Female Maximal and Anaerobic Threshold Cardiorespiratory Responses to Six Different Water Aerobics Exercises. Research Quarterly for Exercise and Sport. 2015, vol. 86(3), pp. 267-273.

[14] Gasser, B.A., Hoppeler, H.H. Performance Diagnostic in Cross-Country Skiing. Human Movement. 2015, vol. 16(2), pp. 83-87.

Formenti D., Trecroci A., Cavaggioni L., Caumo A., Alberti G. Heart rate response to a marathon cross-country skiing race: a case study. Sport Sciences for Health. 2015, vol. 11(1), pp. 125-128.

[15] Mendia-Iztueta I., Monahan K., Kyröläine H., Hynynen E. Assessment of heart rate variability thresholds from incremental treadmill tests in five cross-country skiing techniques. PLoS ONE. 2016, vol. 11(1), e0145875. 